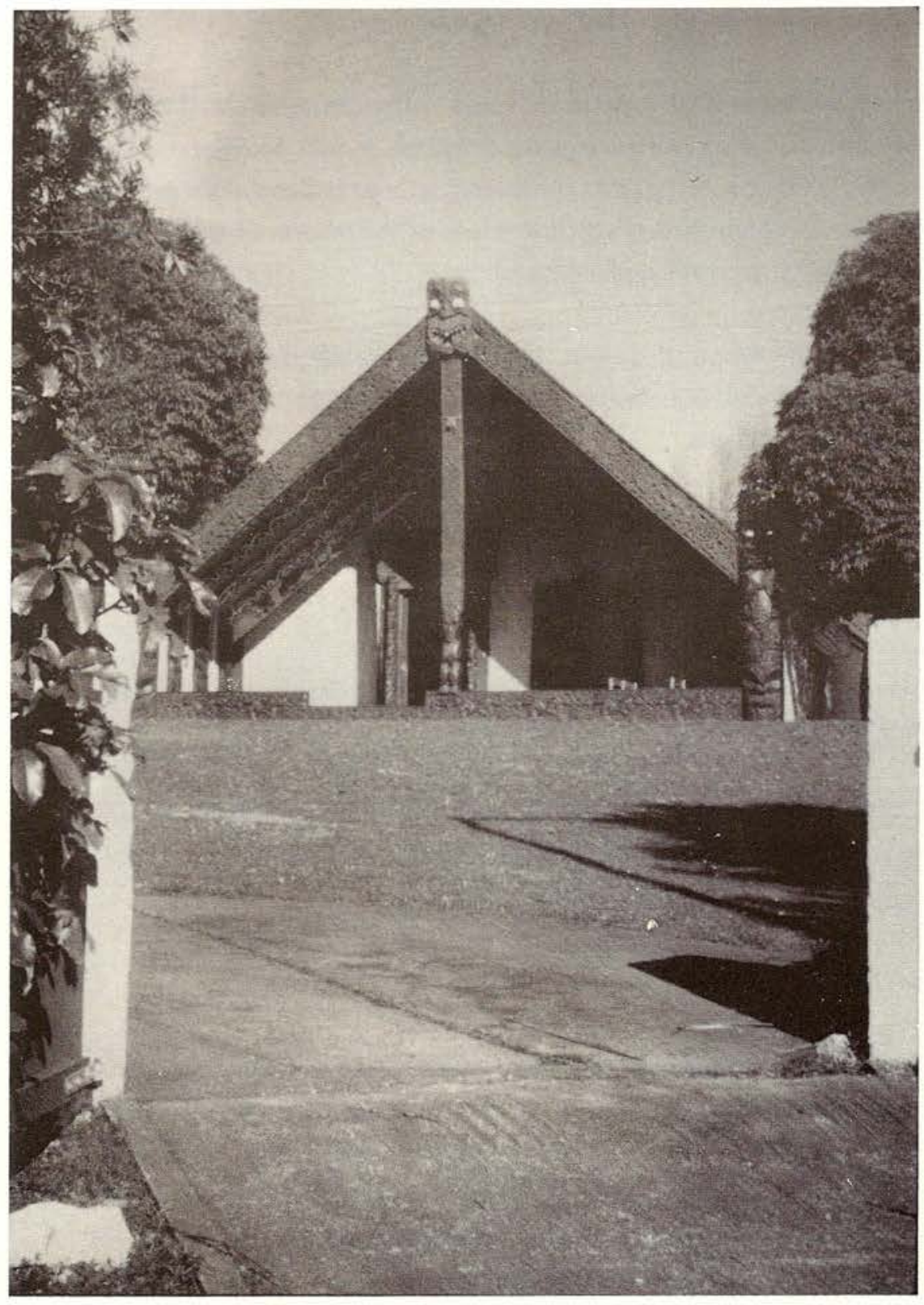




\title{
Speaking To and Talking About: Maori architecture
}

\author{
Michael Linzey
}

When a New Zealand Maori orator standing to speak on a marae addresses the meeting house in the same breath as he also addresses the assembled people - this may be taken as prototypical of a surprising comportment towards architecture within a traditional society. The Maori intuition that the whare whakairo, carved house, is a living presence is richer than any mere simile, it is beyond the idea of metaphor or representation in a European-educated sense. The house is not like an ancestor, it is the ancestor. In European-educated terms this issue may appear peculiar but it is susceptible to phenomenological attention.

The Maori comportment of 'speaking to architecture' is alien to European-educated ways of thinking. Europeans are permitted to speak to one another, but may only talk about architecture. The respective linguistic comportments, 'speaking to' and 'talking about' are distinctly different ways of seeing and understanding architecture.

We set out to contradict the common racialist myth that the architectural comportment of the Maori is more 'primitive', while the European-educated perception of objective profanity is more 'advanced'. It is argued on the contrary that Europeans are excluded by prejudice and a certain linguistic prohibition from a potent world of architectural meaning. But to access some of the nourishing possibilities of the indigenous architecture it is necessary to confront impeding myths within the European-educated outlook - certain philosophical attitudes which prevent us addressing architecture in its imaginative fullness.

\section{PAPER TALK}

This paper talks about a peculiar aspect of the New Zealand Maori dwelling experience - that Maori people directly address and include the carved house, whare whakairo in the rhetoric of tribal occasions and public gatherings, that a work of architecture is a living presence in the hearts of people. In ceremonial greeting for example, when one group of people come to visit another on their traditional land,

\begin{abstract}
Michael Linzey studied engineering at Canterbury University later graduating with a PhD from Melbourne $\mathrm{He}$ is a Senior Lecturer in construction, computer applications at the Department of Architecture, University of Auckland. He is pursuing an investigation into the relationship between myth, metaphor and architecture.
\end{abstract}

opp. Te Tokangunui-a-noho, opened 1874 , stands today in the town of Te Kuiti photo: Michael Linzey. 
1. J.-F. Lyotard, The Postmodern Condition, Minneapolis, University of Minnesota Press; 1984. an orator will extend greetings to the land or marae lying before him; he will greet the house as an ancestral presence standing on the land; he will acknowledge the ever present mythical-spiritual world of Papa and Rangi, earth and sky; only then will he address the people gathered together.

We cannot simply talk about this traditional phenomenon, remarkable as it is, without also acknowledging a certain tensioning and quickening of interest within the European-educated consciousness. The Maori comportment has survived within a predominantly European ambience of New Zealand life. We are not talking here about pre-European Maori. Nothing modern Maori do is isolated from the European majority culture, just as in New Zealand nothing European is isolated from the Maori presence. (Much as some of us might resist the fact, we are a bicultural country.) Europeans however, in the new world as in the old, do not speak to their houses or to architecture. Europeans are permitted to speak to one another, and some Europeans speak to God; but there is a tacit prohibition - it is not extreme to say in Maori terms that it is a tapu - Europeans dare not speak to 'mere things' for fear of looking completely ridiculous. (Dr Dolittle was considered eccentric and amusing because he spoke to animals.)

European-educated interest in the Maori comportment of emotion and appreciativeness towards architecture is tensioned by a spirit of lamentation. We lament the loss of meaning in our own European architecture. Some even go so far as to say that architecture is dead. And there is reason to suspect that this absence of meaning, this reduction in living value of modern European architecture stems from a prohibition, which a Maori might describe as a tapu, but which derives from the European-educated tradition itself.

While the paper talks about a peculiarly Maori phenomenon, it is also at the same time speaking to an international readership. (I do not in fact know who is the readership of this paper; but it is strange is it not, that in the European-educated world, although it is not acceptable to speak to architecture, yet it is completely appropriate for a mere paper to 'speak to' an invisible and possibly even nonexistent audience?) Whatever may be in fact the case, I presume that you are European-educated and that this sense of loss and lamentation has been brought to a certain fashionable pitch for you in the post-modern condition of intellectual and theoretical life. Lyotard 1 for example portrays traditional societies as dominated by 'grand narratives'; traditional mythical and legendary narratives condense descriptive with normative and aesthetic elements, legitimate the social institutions, and serve as models for inclusion of individuals into those institutions. The European-educated tradition on the other hand, in particular the tradition of modern science, purports to be purely descriptive, to have cut itself free from ethical, aesthetical and religious connotations. The purely descriptive language games of modern science generally set out to delegitimise traditional narrative forms. 
Specifically in relation to architecture, Perez-Goméz 2 traces the slow demise of 'mytho-poetic' dimensions in European architecture, related to the crisis of modern science. So that the principle of functionality is no longer seen as a positive and sufficient attribute of modern architecture but is felt instead in terms of an absence or a lamentable loss, a setting aside of the traditional mytho-poetic dimensions.

The richly carved and decorated elements of Maori architecture make many direct references to traditions, poems, and myths, and must ultimately be comprehended by us in terms of the mytho-poetic dimensions of traditional life. The paper will touch upon some of these but by no means exhaustively. Instead in particular we address Maori architecture in terms of the comportment of the orator, in terms of this one peculiar image of an orator standing on the marae and speaking to the carved house.

The paper attempts also to turn our observations onto ourselves. As we explore the mytho-poetical foundations of a Maori behaviour, at the same time we contrast these with the European-educated narratives that seem to underpin our own architectural behaviours, and in this way to explain our own cultural inhibition or prohibition against speaking to architecture.

\section{HUMAN METAPHOR IN ARCHITECTURE}

The whare whakairo is often profusely decorated with human figures both realistic and abstract. The house is in a sense made, designed to be spoken to. There is usually a carved head piece, the koruru, at the apex of the gable, to which speech is directed. And inside the house along the walls at intervals are carved poupou or side-posts, and rafters painted with traditional patterns. The central line of posts supporting the ridge beam, and the ridge beam itself are also carved or painted with human and mythological forms. All this carved timber is no mere ornament added on to the architecture, as it might be interpreted in a European sense. Usually the house itself is named for a specific ancestor and it actually is in its whole construction the embodiment of that person; so that the ridge beam is his or her spine, the rafters are the ribs, the interior space is the belly, the outstretched bargeboards, raparapa, are the arms with fingers extended in greeting.

Te Tokanganui-a-noho is a whare whakairo standing at Te Kuiti in the central North Island. Perhaps the oldest fully carved meeting house in New Zealand today outside of a museum, Te Tokanganui was first built in 1874 although the house has been relocated and partially rebuilt several times in its history. The original architect was Te Kooti Rikirangi, an outstanding military and religious leader of the late nineteenth century, born on the East Coast, who was forced for a time to seek asylum with the Maniapoto people. According to Phillipps 3 the house was
2. A. Perez-Gomez, Architecture and the Crisis of Modern Science, Cambridge Mass: The MIT Press; 1983.

3. W. J. Phillipps, "The Te Kuiti house', Art in New Zealand 10: 1; 1938; pp. 82 9. 
presented to Ngati Maniapoto in recognition of the hospitality which they extended to Te Kooti during his enforced sojourn amongst them. The house was originally named Rawaho-o-te-Rangi who was an important tribal ancestor.

On the East Coast of New Zealand there is a story about Rua-te-pupuke who first acquired the art of carving from Tangaroa, the god of the wild ocean. Tangaroa had kidnapped Rua's son, carried him away to his land under the sea, and there transfixed him upon the gable of his house. After a long search Rua came to the house beneath the sea. He recognised his son in the carving and angrily set fire to the house, removing his son and several other carvings from the outside of the house. There were carved figures inside the house as well which had the power to speak, but all of these were destroyed in the blaze. It is said, because Rua only took carvings from the outside of the house, therefore carvings now cannot speak.

This founding narrative of whakairo is an insight into what was thought about, for to tell a story about why carvings do not speak seems to at least canvass the possibility that carvings might have spoken. And anybody who has had the experience of sleeping a night 'in the belly of the ancestor', surrounded by richly carved poupou and other fine works of Maori art will readily acknowledge the power that this possibility presents to the imagination.

In the European architectural tradition also, we 'people' our work metaphorically in a number of ways. Le Corbusier for example, imprinted the stamp of his own personality upon his work. The Maison La Roche in Paris, an early work of Le Corbusier, contains his 'trademarks' - pilotis, ramps, roof gardens. And the controlled and measured spaces, in particular the picture gallery and the main entrance way, speak to us of Le Corbusier. Entering the house today one almost feels his 'ghost' stalking the empty spaces; but this is not exactly what is meant. It is not ghosts or phantoms haunting a place, nor indeed is it any mere egotistical trademarks that mark good architecture in the European tradition. For we do not advocate that architects should impose their private egos on their work as mere contrivance and idiosyncrasy. This is generally read as a weakness in architecture. But it is as if the building itself haunts and dwells and somehow persists in our imagination, so that for example many years later one spontaneously and vividly recalls the shape or detail, or some characteristic ambience, in precisely the same way a much loved or a strongly delineated person will dwell fondly in the imagination and in memory. When architecture 'becomes a person' in this way in the appreciative imagination, we also see the authority of the architect shining through it as a creating and shaping force, like a family resemblance. Such architecture has 'human scale'; it speaks to us at a number of different levels of meaning simultaneously, with some of the same richness as a lively human dialogue. 
But European architecture's licence to speak to us is strictly proscribed by certain rules of metaphor. Architecture speaks to us, only metaphorically. (And we may not speak in turn to architecture, either metaphorically or any other way.) Geoffrey Scott describes architecture, particularly that of the Renaissance period, in terms of 'the universal metaphor of the human body.' He writes,

The tendency to project the image of our functions into concrete forms is the basis, for architecture, of creative design. The tendency to recognize, in concrete forms, the image of those functions is the true basis, in its turn, of critical appreciation. 4

However there is nothing at all in this very European-educated analysis of architectural humanism that would sanction us to speak to architecture. Scott's project is rigorously proscribed by two typically European-educated barriers or fences - the one that is set up between metaphor and reality, and secondly that between body and mind. For the human functions here spoken of by Scott are strictly confined to the bodily functions and architecture is transcription of the body's forms into forms of building. Architecture speaks to our 'body memory' through the physical articulation of Line, Space, and Massing.

\section{CAVES AND SHADOWS}

We now propose to compare certain mytho-poetic imagery of the Maori with similar or related figures in the tradition of European education, and so perhaps draw closer to comprehending the apparently radical difference in the permitted comportments of Maori and European-educated people towards their respective architectures. This course is in line with that strand of post-modern thinking which redirects attention to the myths, metaphors, the grand narratives upon which all theories and philosophies appear to have been founded. The shaping power of underlying narrative, as primal image, is as much significant for European-educated conditions of thought as it is for Maori.

Indeed this attention to the mytho-poetic underpinning of a culture is by no means exclusively post-modern. Sir George Grey, Governor of New Zealand from 1845, wrote '... I found that these chiefs, either in their speeches to me or in their letters, frequently quoted in explanation of their views and intentions fragments of ancient poems or proverbs, or made allusions which rested on an ancient system of mythology...5 $\mathrm{He}$ soon perceived that he could neither successfully govern nor hope to effect conciliations without first coming to terms with these myths and narratives, the paradigms of their social existence. Sir George may perhaps not have been quite as ready to acknowledge that similar primal imagery also underpins and informs Europeaneducated views and intentions.

For example our views about education itself are molded by Plato's well known
4. G. Scott, The Architecture of Humanism, London: Methuen \& Co. Ltd, 1961; p. 213.

5. G. Grey, Polynesian Mythology, Christchurch: Whitcoulls Ltd, 1974. 


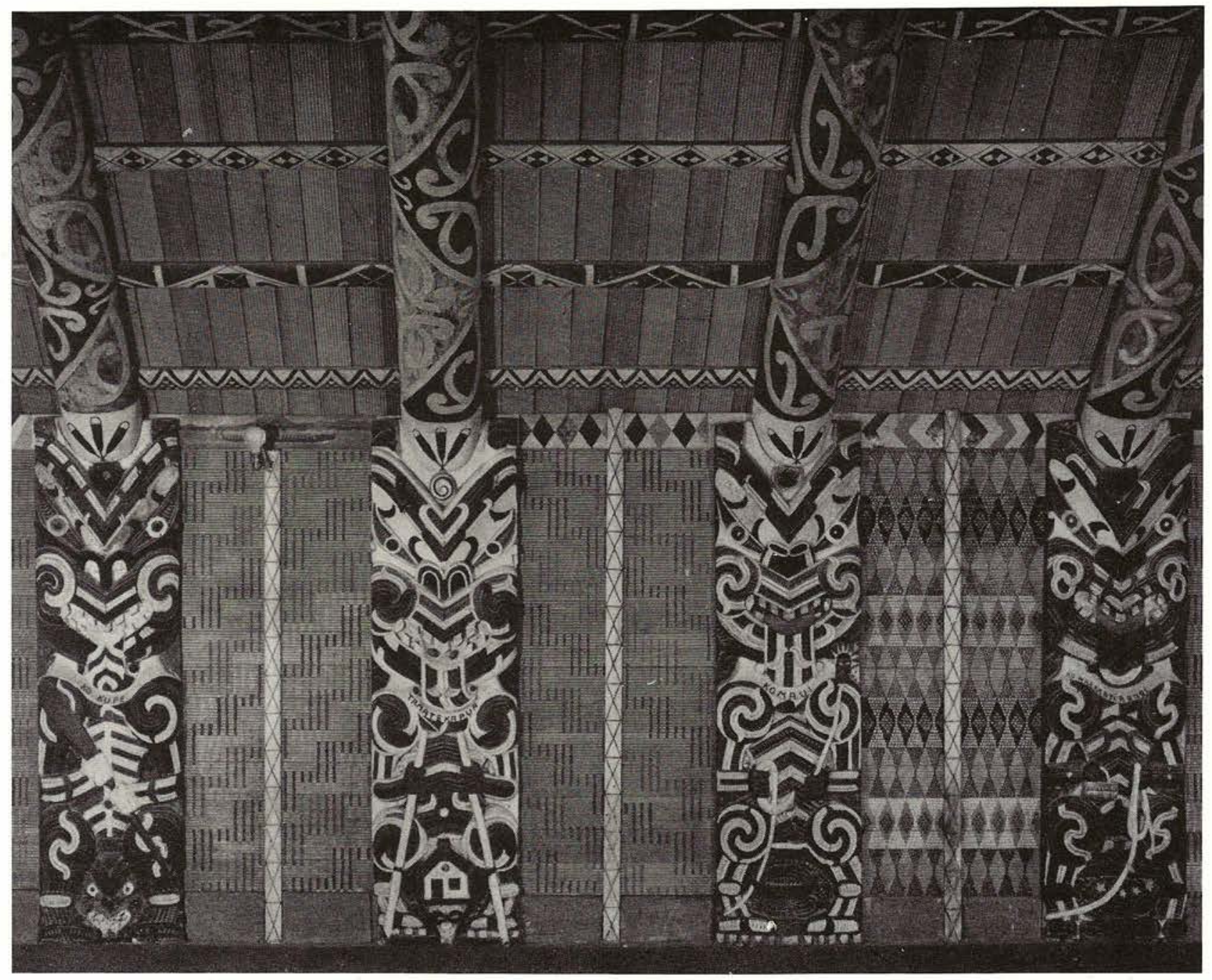


story of the cave. The peculiar affection we have for notions of transcendence, our readiness to adopt two-world views about things as diverse as education, divinity, and metaphysics can be shown to presume upon this simple but evocative tale from the Republic, in which ordinary people are depicted lying enchained in a cave, and ordinary phenomena are somehow represented to them as if they were merely shadows projected on a curtain hung within the cave. Education, according to Plato, draws people up out of this cave into the light of the sun. The sun, transcending the shadowy world of transitory and expedient appearances, symbolises the Form of the good; it is also logos, the second person of the Christian Trinity, also reason, rationality, etc. etc.

Plato forced onto European education a predilection for a radically other world, a two-world image of the cave wherein all was shadows and illusions, and the educated world animated by light and form; in so doing he set up a massive disturbance within the course of European philosophy. 6

In New Zealand there is another cave-narrative altogether, which presents us with an opposite image of the place and aspirations of man. It is the story of Maui, the trickster, the thief of fire, the inventor of rope. It is, among other things, the story of how that invaluable commodity, rope was first discovered. Maui is presented as being already outside of the cave, already in the world of light, and instead it is the sun that is ensconced in a cave. Maui travelled with his brothers to the mouth of a cave on the Eastern edge of the world out of which the sun would shortly set forth to take its daily course across the sky. The story goes that the sun had been misbehaving, travelling far too quickly across the sky, and Maui set about to teach the sun a lesson. But first he had to show his brothers how to make rope. They learned the mode of plaiting flax fibre into stout square shaped ropes, tuamaka, and the manner of plaiting flat ropes, paharahara, and of spinning round ropes.7 With these they snared the sun and held it down and beat it severely, so that the sun itself was subjugated to the will of man.

It is interesting to compare these myths from another culture. We have noted that European-educated people naturally believe that we may only speak to other transcendent entities; to other souls, and to God. It offends our common sense to speak to architecture because architecture is not a sun-like thing. At different times in European history it would have been considered 'unreasonable', 'irrational', 'unenlightened', and also 'unchristian' to speak to an inanimate thing. The prohibition may be traced to the mythology of sun-worship, the myth of transcendence, the primal image of Plato's cave. In the New Zealand culture, whose grand narratives are altogether other myths, there is not this same prohibition in force against speaking to inanimate things.

The Maori focus on the primal image of Maui's invention of rope, and his clever use
6. 'Presence disappearing in its own radiance, the hidden source of light, of truth, and of meaning, the erasure of the visage of Being - such must be the insistent return of that which subjects metaphysics to metaphor.... The sensory sun, which rises in the East, becomes interiorized, in the evening of its journey, in the eye and the heart of the Westerner. He summarizes, assumes, and achieves the essence of man, 'illuminated by the true light' 'J. Derrida, 'White mythology' in Margins of Philosophy translated by A. Bass, Brighton: The Harvester Press, 1982; p. 268.

7. Grey, op. cit.

opp. An interior view of part of the side wall of the $\mathrm{Te}$ Tokangunui-a-noho shows carved posts, poupou alternating with panels of woven tukutuku. The second poupou from the right shows the mytho-poetic figure Maui holding two ropes, with one he has snared a Europeanised depiction of the sun god, Te $\mathrm{Ra}$. The style of the carvirg painting and weaving combines pre-European forms and Ringatu(Christian) symbolism in a way that is characteristic of $\mathrm{Te}$ Huringa(the Turnig, or early European Contact period). photo: Anthropology Department, University of Auckland. 
8. The Maori word for rope, 'kaha', also means: strength; persistence; the line of hills and the boundary line of land; umbilical cord; line of ancestry; and various other meanings which have to do with divination. See H. W. Williams, A Dictionary of the Maori Language, 7th Ed., Wellington: New Zealand Government Printer, 1985.

9. Makereti, The Oldtime Maori, London: Victor Golancz Ltd, 1938. of rope, disturbs the traditional European-educated tendency to naturally believe, or somehow to accept the notion without really believing, in discrete categories of existence, even to the extent of forcing a chasm of unknowing between forms and appearances; the Maori narrative attends instead to the reality of tension between categories. The Maori image attends to the weave and structure of rope itself.

Maui once tricked his brothers to take him fishing. With a hook made from an ancestor's jaw-bone, and with a strong fishing line made of course from rope of his own invention, Maui managed to snare the door-sill of the house of Tonga-nui. He pulled upon his line and fished up the whole North Island of New Zealand, which is known to this day, poetically, as Te Ika a Maui, Maui's fish.

It can be difficult for us to appreciate how powerful this primal image of Maui's rope 8 may have been in neolithic everyday life. In the days before there were reliable metals there could be no tension, only compression, only earth bound structures in the Maori world, except for the tensile, fibrous kinds of things like ropes, woven mats, cloaks, fishing nets, eel traps, and crayfish pots. The houses themselves in pre-European times derived structural integrity from ropes called tua whenua slung across the back of each portal frame formed by pairs of poupou and heke (posts and rafters), and tensioned with large wooden levers against the massive tahuhu, ridge-beam. 'The creaking of timbers was heard under the strain.' 9 This is why the tahuhu and pou tahuhu are required to be such massively large members in Maori house construction, in order to sustain the tension forces induced by the tua whenua. In the European colonial tradition of light timber frame construction and in the Chicago balloon frame, the ridge board carries no constructional load whatsoever and is there only in order to form the line of the roof. Structural integrity is achieved with steel nails instead of rope. It is instructive here to recall how highly valued were metal nails as trade items in the first European contacts.

In the beginning of European imperial history, Alexander the Great announced his colonial intentions in a way that appears bizarre today, but which may have been more highly significant in the context of his own time, when he took up his bronze sword and cut the gordios knot. We note that Alexander was educated in the spirit of Platonic enlightenment by Aristotle himself.

In New Zealand, European-educated missionaries were not slow to class the Maori as 'benighted savages'. The New Zealand mythos seems from our European point of view almost to have gone out of its way to devalue enlightenment. Maui and his brothers subjugated the sun when it misbehaved, travelling too quickly across the sky. And the New Zealand version of the creation myth, when earth and sky were separated, differs subtly from most places in Eastern Polynesia. In most of the island groups the primal father is called Atea, Expanse of Light, but here he is Rangi, which simply and matter of factly means Sky. 
We may also note that the Polynesian word, mana, which means the power or virtue that a person acquires in the social weave and tension of the family and kin group, does not translate exactly as 'charisma' or 'aura' in precisely the same way that a rope does not translate as an instrument of transcendence. The unique meaning of this Polynesian word, mana, is reflected in the considerable currency it has already achieved in European languages, certainly within New Zealand.

\section{HERMENEUTICS OF DIALOGUE}

The philosophical project to deconstruct Plato's 'two-world' image of education, to debunk the cave metaphor was already begun by Aristotle10, and it has been well in train since Galileo, in the whole corpus of modern science. Hermeneutics of dialogue directs attention in this regard to the constituting power of language and thought, and in particular raises the issue of the constitutional difference between the linguistic comportments, speaking to and talking about. We proceed by the Husserlian method of epoche. We temporarily suspend whatever metaphysical presuppositions we might hold about the animacy or inanimacy, the transcendence or otherwise of the 'other', and attention is directed instead to the linguistic structure of dialogue itself, the 'mode of address', the comportment by which the other is confronted. Martin Buber's11 radical observation sets the stage here, that if one deliberately sets out to talk about the other, then the other naturally takes on attributes of 'It-ness'. But when one sets out to speak to the other then the 'Youness' of the other is naturally disclosed. The comportment, the way of seeing, addressing and understanding things, is also the way things are constituted. These alternative comportments, speaking to and talking about, are not an irrevocable dichotomy, not a new ontological chasm in the place of the old appearance-reality, light-shadow split. The difference between speaking to and talking about is not a radical difference in the constitution of the vocalising subject; nor is it a property inherent in the predicated object. It is a difference precisely and only in my comportment, a property not of me or of you or it, but precisely of the linguistic realm between us. They are different modes of address, poles of possible and actual meaning. Buber calls them 'basic words.'

Buber's basic words I-It and I-You are linguistic comportments. But language cannot be divorced from thought and imagination. For in terms of the surface grammar of language alone, 'you' and 'it' are both merely pronouns, and they are equal in valence. But to talk about something is to see and comprehend it as an it, as a mere thing. To speak to something is to see and comprehend a person, or something personified. The constituting meaning of the pronouns, and in particular the significant difference in meaning that there is between them, only appears after the pronouns are understood and experienced, when consciousness fleshes out the potent linguistic forms in active intuition.
10. 'In opposition to the privileged ontological status that Plato accords to the idea, Aristotle emphatically asserts that the primary reality is the particular individual ... but even so he remains within the framework of Plato's orientation towards the logoi." H.-G. Gadamer, The Idea of the Good in Platonic - Aristotelian Philosophy, translated by $\mathrm{P}$. C. Smith, New Haven \& London: Yale University Press, 1986.

11. M. Buber, I and Thou, translated by W. Kaufmann, Edinburgh: T \& T Clark, 1970. 
12. H.-G. Gadamer, Truth and Method, 2nd Ed., translated by G. Barden and J. Cummings, New York: Continuum Publishing Company, 1975; pp. xxiii and 321-2.

13. M. Theunissen, The Other translated by C. Macann, Cambridge: The MIT Press, 1984; p. 275.
One cannot experience the full weight of this comportment of speaking to unless one is also prepared to listen to the other, and to admit that something standing over against one demands to be recognised, to let oneself be told something by it.12 Gadamer describes the undercutting of the full value of speaking to exhibited by speaking down to or up to someone. He emphasises that speaking to is a comportment of equality. The comportment of speaking to is not fully achieved when the other is treated as a means to a selfish end, as a tool that can be known and used; or when the dialectic of the relationship is used to 'reflect oneself out', as for example when one claims to understand the other better than he understands himself. The other then loses the immediacy with which it would otherwise make its claim. Without this immediacy and equality, unless one is prepared also to listen, there cannot be a fully human relationship.

Theunissen 13 identifies three formal features by which the comportment of talking about may be contrasted with speaking to. Spatially, talking about is 'perspectivally ordered.' I is the midpoint of a constituted world, 'it', the 'other', is the sphere of having, centred on the subject. But speaking to is not centred spatially on the I, nor on the You, but it is symmetrical and equal. A conversation is carried out precisely in the realm between people, in a dimension that is equally accessible to them both. Secondly, in social terms, talking about 'secures for the human being the mastery of his essence.' The other is determined; I determine. It is a product; I am the producer. It is the slave; I am the master. But speaking to by contrast, is a relation of mutuality. There is no connotation of superordinacy and subordinacy. And a third distinction that Theunissen identifies is that to talk about something is to ensnare it in a 'world project.' It is mediated by a horizontal space with which I surround objects in their objectification, a '... conceptuality that fixes beings with a determinate sense and orders them into the system of unified signs.' But the comportment of speaking to is not constrained by this semiotic model, because although the I is separated from the other, they are not separated 'through the barrier of the meaning-instituted project.' You are not in general the signified term in speaking to.

This last also reflects a difference in the way that we can denominate the third person pronoun, compared to the second person pronoun. ' $\mathrm{It}^{\prime}$ or 'he' or 'she' must of necessity stand in the place of the name of something; but 'you' can remain unnamed in this precise sense. For me to say, 'I love her', is to talk about someone. But who precisely is being talked about? We immediately demand to know. Who do I love? Name her! The sentence, 'I love her', as it stands is almost meaningless without the name. The project is blatantly incomplete. But if instead I say, 'I love you', then your name becomes almost superfluous to the meaning of the sentence. To use the name in speaking to serves only to make the sentiment slightly more formal. But not to use the name in talking about, to refuse to nominate what is being talked about, is deliberately to mystify a situation. 
When I am talking about something, the name of that thing has to be readily and explicitly available to my consciousness. It is the that-ness of reference, by which representation is achieved. I cannot honestly and legitimately talk about something but I must be immediately prepared to name it. But when I speak to someone, their name is submerged, interiorised, only tacitly beheld. Regardless even whether I know what your name is or not, I am hardly ever forced to use this knowledge in speaking to you directly. Consequently, namelessness is no impediment in the comportment of speaking to as it is in talking about.

There are many kinds of thing, strange things, new things, unborn things, beautiful things, and numinous things, that we experience difficulty in talking about because to talk about them requires us to name them, to fix them in the system of unified signs, demands that we know their name; and in attempting to name them it is as if their very meaning dissolves or shifts awkwardly. These are situations it may be wrong to talk about, for to do so requires us either to pretend to know the name or to misname something that may be intrinsically unnameable. It is also highly inappropriate to blandly ignore these things, to turn one's back on them. A more appropriate and respectful comportment to take towards nameless things is to address them directly, to draw them into imaginative dialogue, to find out who they are by speaking to them. Because speaking to is the one mode of address that does not demand an explicit name.

Speaking to, using the second person pronoun rather than the third, enables us to address a subject directly, even although it may be nameless, even if, by its nature it is unnameable. Speaking to is a linguistic structure that is appropriate for an encounter with the 'Living Presence' for precisely this reason that the gods are also often unnameable. This is not to say that the other has to be nameless in order to be spoken to, but that speaking to may demand and obtain the appropriate degree of respect and effective openness. The Maori meeting house has the name of a tribal ancestor, and in ceremonial and other situations the house may indeed be addressed by name. These houses are held in the deepest respect, veneration, affection, but they are not worshipped as God or as gods. When Maori people speak to their house, the house itself takes on a corresponding numinous quality - the quality of the living presence of the ancestor - but it is not the awful unnameable numinous quality of the Living Presence of God.

Of course a Maori also is free to talk about the meeting house. The peculiarly Maori comportment of speaking to architecture, (which we are suggesting is only peculiar in this respect that it is not European-educated, not prohibited by the effaced mythology of sun-worship,) does not preclude the Maori from also and in other circumstances, talking about architecture. (Although the quality of respect, and the general tone of voice is different in talking about a whare whakairo compared to 
14. M. R. Austin, 'A description of the Maori marae', in A. Rapoport, ed., The Mutual Interaction of People and their Built Environment, The Hague: Mouton, 1976; pp. 229-241. talking about European buildings - a Maori elder at a marae work committee meeting might say that the meeting house needs a new coat of paint on the roof, or perhaps that 'he would like' to be repainted.)

... this often-referred-to 'symbolism' [of the meeting-house] is quite literal', writes Aisstin,14 'but Maori attempts to explain 'in pakeha terms' their feeling for the marae... come out as either obscure expressions such as 'a symbol of Maoritanga [Maoriness]', or 'being a Maori', 'where I meet my ancestors', or apparent trivialities such as 'the food', 'the people', 'sleeping alongside my kin', and so on.' But this apparent incompetence to talk about what is the central dimension of their own architecture is by no means peculiar to the Maori; it is not a cultural deficiency somehow concomitant with their demonstrated competence to speak to architecture. For European-educated people prove to be equally incompetent in this respect. The main cultural difference seems to be that European-educated people are also incompetent to speak to architecture.

Speaking to is a natural and a sensitive comportment with which we may address certain aspects of the human environment. It is a comportment that Maori use in everyday life in contemporary New Zealand to show respect for their architecture. But in the European-educated view it still does appear to be mighty peculiar to speak directly to a building which we understand to be inanimate and unenlightened. We have suggested a possible explanation why this may be the case: that Europeans are inhibited in their comportment by a kind of intellectual prohibition which stems from a founding myth of European education itself. It may or may not prove to be possible or even desirable for us to deconstruct this linguistic impediment that we have, to lift the tapu, thus perhaps to enhance the European-educated comportment towards European architecture. But in contemporary New Zealand society such a programme of philosophical deconstruction would not be merely an academic exercise or a contribution to architecture in theory alone. It might also prove to be a positive and necessary step towards forming a healthy pluralistic society. 